\title{
Strategies to achieve fairer prices for generic and biosimilar medicines
}

\author{
Early market entry and rapid uptake of quality assured generic and biosimilars are key to improving \\ access to medicines, say Alessandra Ferrario and colleagues
}

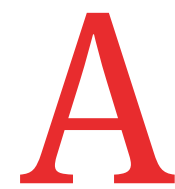

ccess to safe, effective, quality assured, and affordable essential medicines and vaccines for all has been identified as key to achieving universal health coverage and financial protection. ${ }^{1}$ As such, it is one of the targets of the sustainable development goals.

The availability and use of fairly priced, quality assured generic and biosimilar medicines can make an important contribution in improving access to medicines. Notable examples of generic medicines enabling greater access to care include treatment of HIV and hepatitis $\mathrm{C}$ in low and middle income countries. ${ }^{23}$ Availability of generic medicines has also been linked with increased use of three antineoplastic medicines (capecitabine, imatinib, and decitabine) in China and of an antiplatelet medication (clopidogrel) in lower income European countries. ${ }^{45}$

Despite progress in the availability and use of generic and biosimilar medicines, there is potential for more competitive prices and greater uptake. A study comparing the cost of generic medicines in Europe in 2013 found wide variation in both prices and market share. For example, prices charged by manufacturers

\section{KEY MESSAGES}

- Despite the introduction of policies to increase use of generics and biosimilars, large differences remain in the price and uptake of these medicines between countries

- Trust in the quality, safety, and bioequivalence of generics and biosimilars is essential to increase their use

- Timely entry in the market is also important for uptake

- Further, an analysis of the market and a process of change including relevant stakeholders (eg, health professionals, payers, patients, health authorities) are essential to design policies which will promote a healthy market where fairly priced medicines are available on a timely and sustainable basis to wholesalers in Switzerland were more than six times those in the United Kingdom, based on the results of a commonly used price index. ${ }^{6}$ While prices of medicines with generic competition have been shown to drop up to $66 \%$ compared with the originator price (before patent expiry), ${ }^{7}$ similar reductions have not been seen for biosimilars. This is, at least in part, a result of the complex production process and greater regulatory requirements to obtain marketing authorisation for biosimilars compared with generic medicines, which create barriers to market entry for competitors. $^{8}$

The proportion of prescriptions filled with generic medicines varies widely between countries. For example, in Europe the proportion of generic prescribing ranged from 17\% in Switzerland to $83 \%$ in the United Kingdom in 2013. ${ }^{6}$ Other settings show less variation and higher uptake of generic medicines. A study of market dynamics in the private sector in 19 low and middle income countries and the United States between 2001 and 2011 found relatively high generic uptake, with more than $60 \%$ of market share. ${ }^{9}$ In the 10 Latin American and Caribbean countries included in the analysis the generic market share increased from $66 \%$ to $78 \%$ between 2001 and 2011.9

Authorities, such as ministries of health and health insurance funds, have introduced several different supply and demand side policies and competition measures to reduce the prices of generic and biosimilar medicines and increase their uptake. ${ }^{10}$ In this analysis, we review the effect of some of these policies and discuss factors that may influence their outcome.

\section{Internal reference pricing}

Internal reference pricing is a reimbursement policy used in several countries worldwide. ${ }^{610}$ Insurers implementing this policy establish groups of interchangeable medicines, and a reimbursement price for all medicines in the group is set. The internal reference pricing group is made up of either medicines with the same active ingredient or medicines with different active ingredients but considered to have similar efficacy and safety profiles. The model works by making patients pay the difference if the price of the medicine dispensed at the pharmacy is higher than the reference price. There is mixed evidence on the impact of internal reference pricing on prices and use. However, a 2014 Cochrane review found that internal reference pricing may reduce expenditure by insurers on medicines in the short term by directing patients towards medicines that cost no more than the reference price. ${ }^{11}$

Studies comparing price decreases in internal reference pricing systems versus non-regulated markets found larger price decreases in non-regulated markets. ${ }^{12}$ In internal reference pricing systems, once a certain reference price has been set after patent expiry there is little incentive for manufacturers to offer prices below the reference price, whereas competition for market share led to lower prices in free markets. Similar findings were reported for use of internal reference pricing versus tendering for outpatient prescription medicines. ${ }^{13}$ While in most countries internal reference pricing includes only off-patent products, in Germany, for example, on-patent products which have no additional benefit to existing medicines are included in reference pricing groups. ${ }^{14}$

\section{Generic or biosimilar price linked to originator product}

Several European countries mandate specific price reductions on generic and biosimilar medicines based on a percentage of the originator price. ${ }^{1014}$ The specific discount can be negotiated and may therefore vary from one medicine to another. This is the case for biosimilars in Belgium, Ireland, and Spain. Other countries set the same discount for all medicines. For example, generic outpatient prescription medicines in Estonia are at least 15\% cheaper than the reference medicine. ${ }^{15}$ In these countries, different levels of price reduction may still apply, depending on whether the generic or biosimilar product is the first, second, or 
third to enter the market. ${ }^{15}$ Similar to internal reference pricing, mandating fixed discounts could discourage price competition between different manufacturers that might otherwise lead to greater price reductions. Another factor influencing the efficacy of this policy option is the price of the originator or reference product against which the price of the generic or biosimilar medicine is set.

\section{Non-proprietary prescribing and generic substitution}

International non-proprietary prescribing is the practice of prescribing medicines by their generic name rather than their trade name. Generic substitution happens at the pharmacy and entails substituting the prescribed medicine brand with a less expensive medicine with the same strength and active ingredient. This practice may be mandatory, voluntary, or not allowed, depending on the country.

Generic medicines were found to enter the market earlier in European Union countries with mandatory generic substitution. ${ }^{16}$ In the US, dispensing generic medicines rather than their brand equivalent saved Medicare Part D and patients enrolled with it a total of about \$33bn (£27bn; €30bn) in 2007. ${ }^{17} \mathrm{~A}$ further $\$ 900 \mathrm{~m}$ could have been saved if all products with a generic equivalent had been substituted. ${ }^{17}$ Evaluation of generic substitution on price development in Finland showed that the average price of substitutable medicines decreased by more than $10 \%$ during the first year of implementation. ${ }^{18}$ There was wide variation in price development, with some medicines having price increases and others price decreases by more than $50 \%{ }^{18}$ The number of competitors, the type of medicine (originator versus generic), and the price difference between the most and least expensive product for a particular active ingredient were the most important determinants of price changes. ${ }^{18}$

A number of barriers to implementing international non-proprietary prescribing and generic substitution exist. These include perceptions by prescribers, dispensers, and patients about the quality, safety, and bioequivalence of generics with the originator product; perceptions about possible side effects as a result of switching patients to generic medicines; and distrust in authorities and lobbying by interest groups such as trade organisations and manufacturers. ${ }^{619-21}$ In settings where mandatory implementation of these policies in not possible, allowing voluntary implementation would be a first step in this direction.

Switching patients from the reference biological product to its biosimilar has been the subject of debate. The reference biological product is the product that was granted marketing authorisation first and to which the biosimilar product is compared. During its marketing authorisation process, the biosimilar is compared to the reference product for being highly similar and not showing any clinically meaningful differences from the biosimilar. ${ }^{22}{ }^{23}$ While still an area for debate, ${ }^{24}$ studies have shown that the risk of immunogenicity related safety concerns or diminished efficacy is unchanged after switching from a reference biological to a biosimilar medicine. ${ }^{25}$ In some settings, regulatory standards and their implementation present challenges. For example, a review of regulatory pathways and quality of the evidence required for biosimilar approval in Latin American countries highlighted important differences between countries and discrepancies between regulation and practice. $^{20}$

\section{Tendering and pooled procurement}

The price of generic medicines can be reduced by creating economies of scale and pooling procurement across health facilities or administrative areas. Tendering, where suppliers compete for contracts, can be organised at the level of active ingredient (for example, simvastatin) or therapeutic group level (for example, statins). Tendering has been extensively used in hospital and outpatient sectors in a number of countries to procure medicines, vaccines, and other health products at lower prices. ${ }^{2627}$

Potential challenges associated with tendering include excessive price pressure and a "winner takes all" approach. Such practices can drive out competitors from the market, particularly small suppliers which may not be able to offer such low prices and/or supply the entire market. Reducing the number of possible suppliers can decrease competition and make the market vulnerable to shortages if, for any reason, the tender winner is not able to supply the agreed type and quantity of medicines on time. Risk mitigation strategies exist, such as dividing the tender award between more than one manufacturer or supplier and considering more factors, not just price, when awarding a tender. Such factors include, for example, past performance of the supplier, shelf life of the medicines, delivery time, and production capacity. ${ }^{2829}$

\section{Making policies work}

No one policy strategy will lower prices, broaden equitable access, and lead to affordable spending for quality generics and biosimilars. Rather, multiple actions by different stakeholders in the system are needed (table 1). These include laws and regulations, efficient procurement systems, formularies, and reimbursement system restrictions (such as tiered co-payments, incentives for prescribers of generics) as well as individual and group targeted education (including social media campaigns).

Whether the policy measures described achieve their goals of increasing market share and producing a fairer price for generic medicines and biosimilars depends on several factors. These policies are implemented in the real world where other policies can influence expected outcomes and where the beliefs, expectations, and interests of affected stakeholders (such as suppliers, doctors, pharmacists, patients, and civil society) can have a substantial impact. For example, a key concern hampering greater use of generic and biosimilar medicines are the perceptions around medicine quality, possible side effects, and potential risk in switching patients from an originator medicine. These concerns can lead to patients and doctors preferring branded medicines where a less expensive generic medicine could be prescribed. In all settings, educational interventions are needed to increase acceptability of generic and biosimilar medicines to doctors, pharmacists, and patients. Workshops and information campaigns for prescribers, dispensers, and patients to help deal with these issues have been implemented in several countries. ${ }^{30}$ Regulatory systems need to be strengthened in some countries, to assure the bioequivalence of generics and the high degree of similarity between reference and biosimilar products.

Some minimum prerequisites need to be in place to enable policy implementation. These include a healthy market ${ }^{28}$ characterised by a sufficient number of suppliers to generate competition and timely availability of quality assured generic or biosimilar medicines after patent expiry. Best practice and clinical guidelines are required to facilitate generic substitution. ${ }^{31}$ There need to be incentives for pharmacists to dispense generics (for example, mandatory substitution at pharmacy level) and patients to ask for 


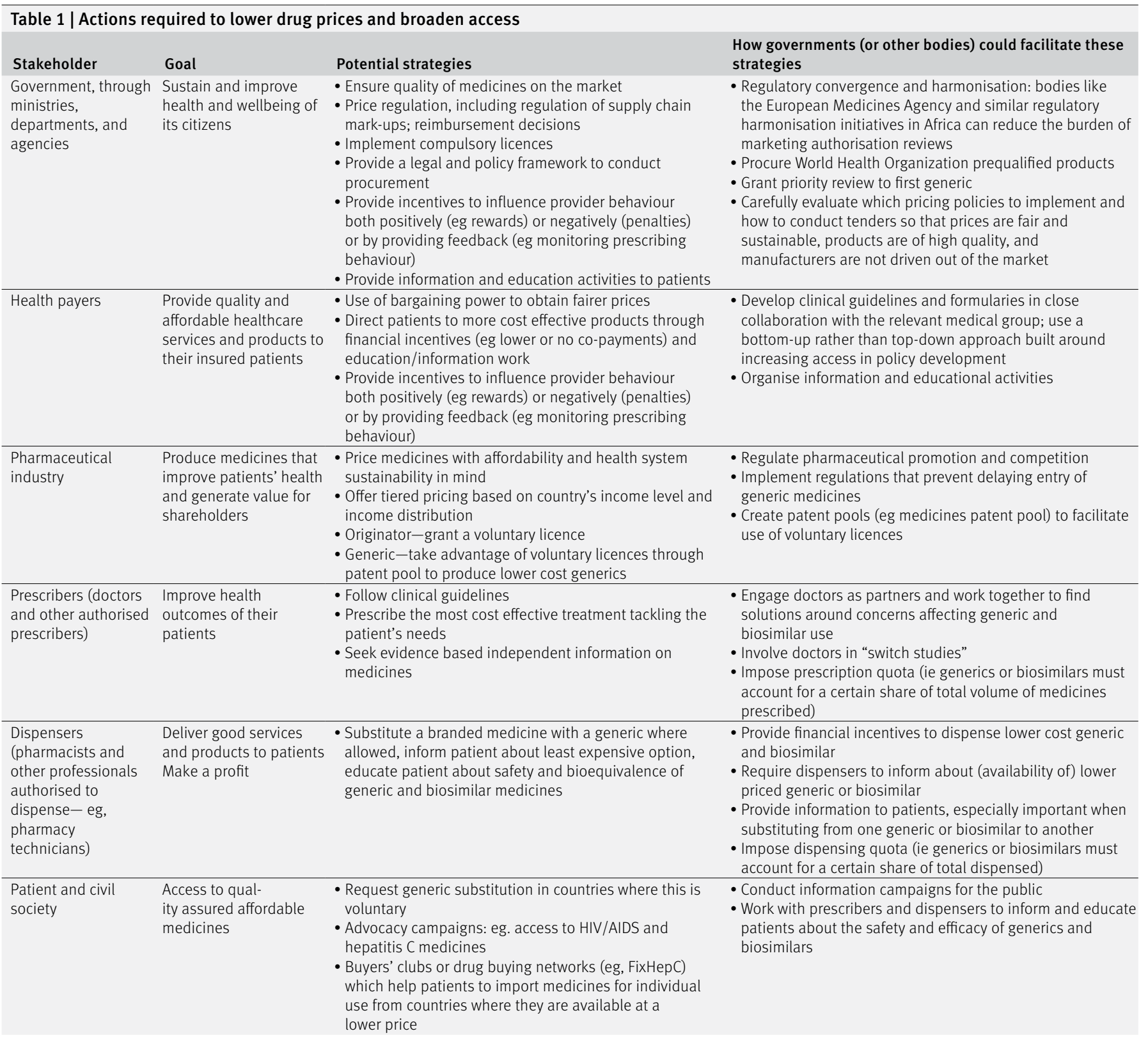

them (for example, lower co-payments, knowledge that they can request a generic) so that generic uptake increases soon after patent expiry. A process of consultation with the different stakeholders concerned (clinicians, patients, payers, procurement bodies) ahead of a new policy implementation, where the concerns of different stakeholders can be discussed and compromise sought, is likely to be more acceptable to those affected by these policies than forcing policy through.

However, a number of challenges remain. As patents near their end, patent extensions, litigations, and payments to generic manufacturers are sometimes used by originator manufacturers to delay entry of generic and biosimilar medicines into new markets. ${ }^{32}$ Furthermore, product hopping can help the originator manufacturer to retain market share after patent expiry and limit generic uptake. It is not uncommon for originator manufacturers to promote a new, similar, high priced, on-patent medicine before the patent on the first medicine expires to retain market share of blockbuster medicines. ${ }^{32} 33$ One such example is memantine, used for treatment of Alzheimer's disease. Close to the end of its patent term, the brand manufacturer launched another medicine that is taken once a day (extended release) instead of twice a day (immediate release).$^{34}$ This reformulation granted the patent holder another 14 years of patent protection on the reformulated product. ${ }^{34}$
Product hopping can reduce the saving which health insurers and patients would have gained had patients switched to the generic. Another challenge limiting savings from the introduction of a generic medicine is the existence of secondary patents for new indications. This means that while an indication has lost patent protection (for example, chronic myeloid leukaemia for imatinib), another indication may still be on patent (for example, gastrointestinal stromal tumours for imatinib).

\section{Conclusions}

If greater benefits are to be gained from generic and biosimilar medicines, a key issue is to increase trust in these products as well as their timely entry and uptake 
by markets. Authorities that are managing reimbursement should carefully evaluate the evidence on long term impact of pricing and purchasing policies when deciding whether to intervene in the off-patent market using internal reference pricing or organising tenders. Creating and sustaining a healthy market, where quality assured products are available at fair and sustainable prices from different suppliers, should be the long term vision over aggressive price cuts. Implementation of international nonproprietary prescribing and generic substitution are key enablers of greater uptake in countries at all levels of income. Emphasis on increasing access for patients and quality of care rather than cost saving is likely to be a more convincing argument to forge successful partnerships with patients, prescribers, and dispensers who are responsible for implementing these policies.

Contributors and sources:AF is a health policy researcher with focus on access to medicines and cancer care. GD is a policy analyst at the Organization for Economic Cooperation and Development (OECD); this article reflects GD's views and not those of the OECD. TH is a technical officer at the WHO European Office for Europe with expertise in procurement. $\mathrm{SV}$ is head of the pharmacoeconomics department of the Austrian Public Health Institute and head of WHO Collaborating Centre for Pharmaceutical Pricing and Reimbursement Policies. FS is professor of pharmaceutical sciences at the University of KwaZuluNatal and chairperson of the South African National Medicines Pricing Committee. HBP is programme manager of health technologies and pharmaceuticals in the Division of Health Systems and Public Health at the WHO European Office for Europe. AF drafted the article and finalised it with the contribution of GD, TH, FS, SV, HBP, who provided critical feedback for important intellectual content. AF is the guarantor of the article. This manuscript is based on a narrative review of the literature and the authors' experience in working on pricing and reimbursement in different settings worldwide.

Competing interests: We have read and understood BMJ policy on declaration of interests and declare that $\mathrm{AF}$ has received personal fees from the WHO Regional Office for Europe during the conduct of the study; grants from Swiss National Science Foundation-Fellowship, and personal fees from European Society for Medical Oncology outside the submitted work.

Provenance and peer review: Commissioned; externally peer reviewed.

This article is part of a series proposed by the WHO and commissioned by The BMJ. The BMJ retained full editorial control over external peer review, editing, and publication of these articles. Open access fees are funded by WHO.

Alessandra Ferrario, research fellow ${ }^{1}$

Guillaume Dedet, policy analyst ${ }^{2}$

Tifenn Humbert, technical officer ${ }^{3}$

Sabine Vogler, head of department ${ }^{4}$

Fatima Suleman, professor $^{5}$

Hanne Bak Pedersen, programme manager ${ }^{3}$

${ }^{1}$ Department of Population Medicine, Harvard Medical School and Harvard Pilgrim Healthcare Institute, Boston, USA
${ }^{2}$ Organisation for Economic Co-operation and Development, Paris, France

${ }^{3}$ World Health Organization, Regional Office for Europe, Copenhagen, Denmark

${ }^{4}$ WHO Collaborating Centre for Pharmaceutical Pricing and Reimbursement Policies, Pharmacoeconomics Department, Gesundheit Österreich GmbH (GÖG/ Austrian Public Health Institute), Vienna, Austria

${ }^{5}$ Discipline of Pharmaceutical Sciences, School of Health Sciences, University of KwaZulu-Natal, Durban, South Africa

Correspondence to: A Ferrario

Alessandra_Ferrario@hphci.harvard.edu

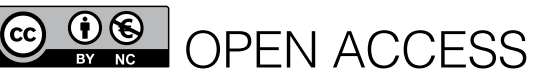

This is an Open Access article distributed under the terms of the Creative Commons Attribution IGO License (https://creativecommons.org/licenses/ by-nc/3.0/igo/), which permits use, distribution, and reproduction for non-commercial purposes in any medium, provided the original work is properly cited.

\section{Check for updates}

1 United Nations. Sustainable development goals. United Nations Sustainable Development, 2018. https://www.un.org/sustainabledevelopment/ sustainable-development-goals/

2 't Hoen EF, Veraldi J, Toebes B, Hogerzeil HV. Medicine procurement and the use of flexibilities in the Agreement on Trade-Related Aspects of Intellectual Property Rights, 2001-2016. Bull World Health Organ 2018;96:185-93. doi:10.2471/ BLT.17.199364

3 Douglass CH, Pedrana A, Lazarus JV, et al. Pathways to ensure universal and affordable access to hepatitis C treatment. BMC Med 2018;16:175. doi:10.1186/ s12916-018-1162-z

4 Elek P, Harsányi A, Zelei T, Csetneki K, Kaló Z. Policy objective of generic medicines from the investment perspective: The case of clopidogrel. Health Policy 2017;121:558-65. doi:10.1016/j. healthpol.2017.02.015

5 Guan X, Tian Y, Ross-Degnan D, Man C, Shi L. Interrupted time-series analysis of the impact of generic market entry of antineoplastic products in China. BMJ Open 2018;8:e022328. doi:10.1136/ bmjopen-2018-022328

6 Wouters OJ, Kanavos PG, McKEE M. Comparing generic drug markets in Europe and the United States: prices, volumes, and spending. Milbank Q 2017;95:554601. doi:10.1111/1468-0009.12279

7 Vondeling GT, Cao Q, Postma MJ, Rozenbaum $\mathrm{MH}$. The impact of patent expiry on drug prices: a systematic literature review. Appl Health Econ Health Policy 2018;16:653-60. doi:10.1007/s40258-018 0406-6

8 Blackstone EA, Joseph PF. The economics of biosimilars. Am Health Drug Benefits 2013;6:469-78.

9 Kaplan WA, Wirtz VJ, Stephens P. The market dynamics of generic medicines in the private sector of 19 low and middle income countries between 2001 and 2011: a descriptive time series analysis. PLoS One 2013;8:e74399. doi:10.1371/journal. pone.0074399

10 Kaplan WA, Wirtz VJ, Nguyen A, Ewen M, Vogler $\mathrm{S}$, Laing R. Policy options for promoting the use of generic medicines in low- and middle-income countries. Health Action International 2018:106. http://haiweb.org/wp-content/uploads/2017/02/ HAl_Review_generics_policies_final.pdf

11 Acosta A, Ciapponi A, Aaserud M, et al. Pharmaceutical policies: effects of reference pricing, other pricing, and purchasing policies. Cochrane Database Syst Rev 2014; 10:CD005979. doi:10.1002/14651858.CD005979.pub2
12 Kanavos PG, Costa-Font J, Seeley E. Competition in off-patent drug markets: issues, regulation and evidence. Economic Policy 2008;23:500-44.

13 Casanova-Juanes J, Mestre-Ferrandiz J, EspínBalbino J. Competition in the off-patent medicine market in Spain: the national reference pricing system versus the regional system of tendering for outpatient prescription medicines in Andalusia. Health Policy 2018;122:1310-5. doi:10.1016/j. healthpol.2018.10.008

14 Vogler S, Haasis M, Dedet G, Lam J, Bak Pedersen $\mathrm{H}$. Medicines reimbursement policies in Europe. 2018.http://www.euro.who.int/en/health-topics/ Health-systems/health-technologies-and-medicines/ publications/2018/medicines-reimbursementpolicies-in-europe

15 Moorkens E, Vulto AG, Huys I, et al. Policies for biosimilar uptake in Europe: an overview. PLoS One 2017;12:e0190147. doi:10.1371/journal. pone. 0190147

16 European Commission. Pharmaceutical sector inquiry-final report. European Commission, 2009.

17 United States Congressional Budget Office. Effects of using generic drugs on Medicare's prescription drug spending. 2010. https://www.cbo.gov/sites/default/ files/111th-congress-2009-2010/reports/09-15prescriptiondrugs.pdf

18 Aalto-Setälä V. The impact of generic substitution on price competition in Finland. Eur J Health Econ 2008;9:185-91. doi:10.1007/s10198-0070059-0

19 Colgan S, Faasse K, Martin LR, Stephens MH, Grey A, Petrie KJ. Perceptions of generic medication in the general population, doctors and pharmacists: a systematic review. BMJ Open 2015; 5:e008915. doi:10.1136/bmjopen-2015-008915

20 Azevedo VF, Babini A, Caballero-Uribe CV, CastañedaHernández G, Borlenghi C, Jones HE. Practical guidance on biosimilars, with a focus on Latin America: what do rheumatologists need to know?J Clin Rheumatol 2019;25:91-100. doi:10.1097/ RHU.0000000000000881

21 Dunne SS, Dunne CP. What do people really think of generic medicines? A systematic review and critical appraisal of literature on stakeholder perceptions of generic drugs. BMC Medicine 2015;13:173. doi:10.1186/s12916-015-0415-3

22 Biosimilar medicines: marketing authorisation. European Medicines Agency, 2018.https://www. ema.europa.eu/en/human-regulatory/marketingauthorisation/biosimilar-medicines-marketingauthorisation

23 Biosimilar and interchangeable products. US Food and Drug Administration, 2019. https:// www.fda.gov/drugs/biosimilars/biosimilar-andinterchangeable-products

24 Pires A, Goyal K, Greenspan A. Comment on: "Switching Reference Medicines to Biosimilars: A Systematic Literature Review of Clinical Outcomes". Drugs 2018;78:851-2. doi:10.1007/s40265-0180918-2

25 Cohen HP, Blauvelt A, Rifkin RM, Danese S, Gokhale $\mathrm{SB}$, Woollett $\mathrm{G}$. Switching reference medicines to biosimilars: a systematic literature review of clinical outcomes. Drugs 2018;78:463-78. doi:10.1007/ s40265-018-0881-y

26 Seidman G, Atun R. Do changes to supply chains and procurement processes yield cost savings and improve availability of pharmaceuticals, vaccines or health products? A systematic review of evidence from low-income and middle-income countries. BMJ Global Health 2017;2:e000243. doi:10.1136/ bmjgh-2016-000243

27 Ferrario A, Kanavos PG, Humbert T, Iwamoto K, Bak Pedersen $\mathrm{H}$. Challenges and opportunities in improving access to medicines through efficient public procurement in the WHO European Region. World Health Organization Regional Office for Europe, 2016.

28 Unicef. Supply annual report 2015. United Nations Children's Fund Supply Division, 2016. https://www. 
unicef.org/supply/files/UNICEF_Supply_Annual_ Report_2015.pdf

29 van Valen M, Jamieson D, Parvin L, Ramirez

CL. Dispelling myths about drug procurement policy. Lancet Global Health 2018;6:e609-10. doi:10.1016/S2214-109X(18)30190-6

30 Hassali MA, Alrasheedy AA, McLachlan A, et al. The experiences of implementing generic medicine policy in eight countries: A review and recommendations for a successful promotion of generic medicine use. Saudi
Pharm / 2014:22:491-503. doi:10.1016/j. jsps.2013.12.017

31 Johnston A, Asmar R, Dahlöf B, et al. Generic and therapeutic substitution: a viewpoint on achieving best practice in Europe. Br J Clin Pharmacol 2011;72:72730. doi:10.1111/j.1365-2125.2011.03987.x

32 Jones GH, Carrier MA, Silver RT, Kantarijian H. Strategies that delay or prevent the timely availability of affordable generic drugs in the United States. Blood 2016;127:1398-402. doi:10.1182/ blood-2015-11-680058
33 Chen CT, Kesselheim AS. Journey of generic imatinib: a case study in oncology drug pricing. Journal of Oncology Practice 2017;13:352-5. doi:10.1200/ IOP.2016.019737

34 Carrier M, Shadowen S. Pharmaceutical product hopping: a proposed framework for antitrust analysis. Health Affairs Blog 2017. https://www.healthaffairs. org/do/10.1377/hblog20170601.060360/full/

Cite this as: BMJ 2020;368:15444

http://dx.doi.org/10.1136/bmj.15444 